\title{
Os impasses da educação e a formação do professor em geografia $^{1}$
}

Shiziele de Oliveira Shimada*

Resumo: O artigo proposto analisa os impasses da educação e a Formação do Professor em Geografia diante da lógica do capital. Nesse contexto a abordagem perpassa pela dialética que tem nas contradições o entendimento do processo educacional, relacionando a formação do professor de Geografia e o ensino. Para tanto, utiliza-se da pesquisa em livros, dissertações e teses que permitam entender o sistema educacional brasileiro e a inserção da educação voltada à lógica de mercado, ocasionando uma crise no sistema educacional.

\section{The dilemmas of education and teacher training in geography}

Abstract: The proposed article examines the dilemmas of education and teacher training in geography on the logic of capital. In this context the approach embraced by the dialectic that has contradictions in the understanding of the educational process, there the thematic to show the education and capitalism, relating to teacher training of Geography and teaching. For both, we use the research in books, dissertations and theses that allow understanding the Brazilian educational system and inclusion of education focused on market logic, causing a crisis in the educational system.
*Doutoranda em Geografia (NPGEO/UFS) e Bolsistapesquisadora CAPES; Licenciada Bacharel e Mestre em Geografia pela Universidade Federal de Sergipe; Especializada em Docência do Ensino Superior/ FIJ; Pesquisadora do Grupo de Pesquisa Estado, Capital, Trabalho e as Políticas de $\mathrm{Re}$ ordenamentos Territoriais/CNPq

Palavras-chave: MEducação; Sistema capitalista; Formação do professor em Geografia.

Key-Words: Education; Capitalist system; Teacher Training in Geography
1 Este artigo faz parte da
monografia de conclusão do
curso intitulada: A Formação
do Professor em Geografia e
os Rebatimentos Frente aos
Impasses da Educação, como
requisito para obtenção da
Especialidade em Docência do
Ensino Superior/ FIJ (2009).

Geografia Ensino \& Pesquisa, v. 17, n.1, jan./abr. 2013 


\section{A Educação nas amarras do Capital}

A educação é um setor importantíssimo dentro de uma sociedade, nesse sentido Mészáros (2006) aborda que o complexo sistema educacional da sociedade é responsável pela produção e reprodução da estrutura de valores no interior da qual os indivíduos definem seus próprios objetivos e fins específicos. Dessa maneira, no sistema capitalista a educação está voltada para atender às necessidades do capital em seu processo de expansão e acumulação ampliada.

A educação brasileira historicamente esteve associada aos interesses de dominação dos grupos de controle econômico e político, reproduzindo uma ideologia de discriminação e preconceito na formação da classe trabalhadora. Dessa maneira, como aborda Mészáros (2006), a educação na sociedade capitalista tem as funções de produção necessária ao funcionamento da economia e da formação dos quadros e a elaboração dos métodos de controle político; estabelecendo uma educação na atualidade inserida numa crise estrutural de todo o sistema capitalista.

A crise educacional brasileira agrava-se devido o conjunto das políticas adotadas pelo governo brasileiro, as quais obedecem à matriz definida pelo Banco Mundial, pelo Banco Interamericano de Desenvolvimento (BID) e pela CEPAL (Comissão Econômica para a América Latina) para os países considerados em desenvolvimento. Os países alinhados com a política neoliberal vêm limitando as verbas destinadas à educação, alijando a maioria da população dos direitos sociais (PNE, 1997).

ao findar a Segunda Guerra, as instituições financeiras internacionais - FMI, Banco Mundial, BIRD - já tinham articulado, do ponto de vista da economia mundial, os níveis de dependência dos Estados ao capital internacional. Os países da órbita dos Estados Unidos, na América Latina, são pressionados a se associarem a essas instituições para obterem crédito, "quando necessário", junto aos bancos internacionais (SEABRA, 2003, p. 25).

Para compreender a problemática do setor educacional, é necessário analisar o histórico da educação com relação à sociedade brasileira, como aponta Bárbara Freitag (1986) através da evolução histórica da problemática educacional no Brasil. Verifica-se que a classe trabalhadora fica à mercê da política econômica do mercado que atua de acordo com os "manda-chuvas", que em cada período da história foi marcado com uma denominação diferente, sejam Igreja/jesuítas, latifundiários, governantes, FMI e Banco Mundial, mas que no fundo tinham uma mesma finalidade: transformar a educação num engodo, e formar cidadãos submissos às ordens do governo e da classe dominante.

No período colonial a economia brasileira era voltada à exportação de produtos agrários, e para esta produção não era necessária a qualificação já que os trabalhadores eram basicamente escravos. Assim, não existia uma política educacional nesse período e a educação era, portanto, controlada pela Igreja e que através dos jesuítas tinham a função de catequizar a sociedade da época em detrimento da relação de dominação e reprodução da ideologia dominante.

No Império e República a igreja continua a controlar a educação, mas agora os escravos eram aos poucos substituídos pelos imigrantes que também não necessitava de qualificação para trabalhar na terra.

Dessa maneira tem-se o entendimento, como aborda Romanelli (1995), de que:

Geografia Ensino \& Pesquisa, v. 17, n.1 p. 133-146, jan./abr. 2013

Os impasses da educação e a formação do professor em Geografia a herança cultural [brasileira] havia sido criada a partir da importação de modelos de pensamento provenientes da Europa; que a extratificação social predominantemente dual na época colonial, havia destinado à escola apenas parte da aristocracia ociosa; que essa demanda social de educação, mesmo quando englobou no seu perfil os estratos médios urbanos, procurou sempre na escola uma forma de adquirir ou manter status, alimentando, além disso, um preconceito contra o trabalho que não fosse intelectual e uma vez, enfim, que todos esses aspectos se integravam, é possível afirmar-se que a educação escolar existente, com origem na ação pedagógica dos Jesuítas, correspondia às exatas necessidades da sociedade com um todo (ROMANELLI, 1995, p.45-46) 
Com a vinda da família Real, em 1808, que houve a necessidade de técnicos para desempenharem as novas funções administrativas. Dessa maneira, as instituições de ensino formavam cidadãos com intuito de manter a supremacia sobre as classes submissas, como exemplo as escolas militares tinham o intuito de formar cidadãos para a defesa do Estado. Já no fim do Império iniciou a formação de uma política educacional estatal sustentada no fortalecimento do Estado sob a forma de sociedade política.

Na década de 1930, após a crise de 1929 com a superprodução do café, vemos a mudança de aplicação de dinheiro para outros setores. 0 dinheiro oriundo do café é agora direcionado à industrialização na produção de bens de consumo, originando uma nova classe social - os burgueses urbano-industriais. Período em que os militares junto com a classe burguesa implantaram a ditadura do Estado Novo, intervindo nas instituições de ensino, controlando e impondo regras na formação ideológica através de leis e projetos que modificaram a estrutura do sistema educacional.

0 ensino profissionalizante foi instruído para atender as classes mais pobres como estratégia para manipulá-las fazendo com que não tivessem acesso ao ensino superior. Assim a política educacional deste período consistiu em formar cidadãos que atendessem aos interesses econômicos - a indústria - através de mão de obra qualificada onde os filhos dos operários ocupavam os lugares dos pais e mesmo tendo consciência da ideologia de classe dominante aceitavam passivamente a nova situação.

O período após a Segunda Guerra Mundial foi marcado pela industrialização como forma de substituir as importações, através da "injeção" de capital estrangeiro, e o interesse pela lucratividade fizeram com que a inflação crescesse empobrecendo cada vez mais a classe média. Observa-se que a educação mais uma vez esteve a serviço dos interesses econômicos do período, mas agora estava definida no nível da legislação através da LDB, sendo destacadas algumas leis como reforma do ensino superior em 1968 , e de $1^{\circ}$ e $2^{\circ}$ graus de 1971 ; e a institucionalização do MOBRAL e do ensino supletivo.

Nos programas econômicos dos países industrializados a prioridade da educação estava situada no quadro das políticas de ajuste e de estabilização defendidas, no âmbito europeu, pela Organização de Cooperação e Desenvolvimento Econômico (OCDE) e, no âmbito mundial, pelo Banco Mundial. O Banco Mundial tem como objetivo que a educação escolar esteja articulada ao novo paradigma produtivo, para assegurar 0 acesso aos novos códigos da modernidade capitalista, sendo necessária que a capacitação e a investigação avancem em direção a um enfoque sistêmico (LIBÂNEO et al, 2007).

Nesse intuito, a partir de 1990, a educação brasileira atrelou-se a política neoliberal, compactuando com as instituições internacionais, a partir de conferências sobre a educação. Como exemplo, a Conferência Mundial sobre Educação para Todos em que houve a elaboração do documento Plano Decenal de Educação para Todos que estabelecia prioridades para a educação nos países do Terceiro Mundo, especialmente a universalização do ensino fundamental.

No governo de Fernando Henrique Cardoso, em 1995, não houve o devido destaque ao Plano Decenal, assim foi estabelecido algumas metas pontuais, como: descentralização da administração das verbas federais, elaboração do currículo básico nacional, educação à distância, avaliação nacional das escolas, incentivo à formação de professores, parâmetros de qualidade para o livro didático, entre outras. Essas metas foram acompanhadas pela política neoliberal realizada pelos órgãos financeiros internacionais - FMI e Banco Mundial.

Dessa maneira, faz-se presente na política brasileira o discurso da modernização educativa, da flexibilidade, da competitividade, da produtividade, da eficiência e da qualidade dos sistemas educativos, da escola e do ensino, na ótica das reformas neoliberais de adequação às demandas e exigências do mercado (LIBÂNEO et al, 2007).

Nessa lógica tem-se uma educação inserida nas amarras do capital através de metas instituídas pelos "manda-chuvas" internacionais, a serem seguidas rigorosamente pelos países subservientes a essa lógica capitalista de mercado, formando assim uma educação para o mercado. Como exemplo, o ensino de Educação à Distância - EAD.

Geografia Ensino \& Pesquisa, v. 17, n.1 p. 133-146, jan./abr. 2013

Shimada, S. 0 . 


\section{O Ensino EAD na sua Lógica Capitalista}

A globalização capitalista da economia trouxe consigo as transformações tecnológicas que tornaram possível o surgimento da era da informação. As novas tecnologias criaram novos espaços do conhecimento através da sociedade em rede, numa relação de teias sociais. A tecnologia digital caracteriza-se pela velocidade tornando um fenômeno descontínuo; representando um novo tempo, redimensionando o espaço, revolucionando a maneira de ver e compreender.

De acordo com Libâneo et al (2007, p.52), esses acontecimentos do mundo atual afetam a educação escolar de várias maneiras, como:

a. exigem um novo tipo de trabalhador, ou seja, mais flexível e polivalente, o que provoca certa valorização da educação formadora de novas habilidades cognitivas e de competências sociais e pessoais;

b. levam o capitalismo a estabelecer, para a escola, finalidades mais compatíveis com os interesses do mercado;

c. modificam os objetivos e as prioridades da escola;

d. produzem modificações nos interesses, nas necessidades e nos valores escolares;

e. forçam a escola a mudar suas práticas por causa do avanço tecnológico dos meios de comunicação e da introdução da informática;

f. induzem alteração na atitude do professor e no trabalho docente, uma vez que os meios de comunicação e os demais recursos tecnológicos são muito motivadores.

Reconhece-se hoje que devido as transformações no mundo do trabalho, da produção e das relações sociais, surge a importância da educação capaz de formar cidadãos mais participativos e críticos à essa sociedade presente. Assim, a escola não é o único local de aprendizagem, pois através do ciberespaço e da aprendizagem a distância tem-se a informação disponível nas redes de computadores interligados através de serviços que respondem às suas demandas de conhecimento.

0 mundo globalizado que tem a relação educação e tecnologia ocasiona uma transição paradigmática. Dessa maneira, a condição espaço-tempo é diferenciada para cada sujeito envolvido nesse processo, tendo o diálogo e a interatividade como relações relevantes fazem com que a formação educacional e a interação professor - aluno/ formando - formadores à distância, um processo moderno no ideal educativo. E a EAD potencializa essa condição de separação física professor-aluno mediante o processo técnico-pedagógico presente nessa relação, gerando um número crescente de profissionais para o mercado de trabalho na lógica do quantitativo estabelecido pelos órgãos internacionais.

Para Gadotti (2000), o espaço de formação EAD é um espaço potencializado pelas novas tecnologias, com as oportunidades que se abrem para os educadores. Esses espaços de formação têm tudo para permitir maior democratização da informação e do conhecimento, portanto, menos distorção e menos manipulação, menos controle e mais liberdade.

O conhecimento é necessário para a compreensão da sociedade atual que têm as inovações tecnológicas presentes nessa relação educacional cada vez mais dissociada das instituições pertencentes ao apoio do conhecimento. Diante da ação da instituição pública que age no setor educacional, deve-se ter uma educação mais democrática, ao mesmo tempo, menos excludente.

Geografia Ensino \& Pesquisa, v. 17, n.1 p. 133-146, jan./abr. 2013

Os impasses da educação e a formação do professor em Geografia
No entanto, verifica-se que no contexto da análise neoliberal a Educação à Distância - EAD é um dos pontos para o governo brasileiro implementar suas políticas econômicas e educacionais de ajuste através das condições de inserção no mundo globalizado, esta se dá nas exigências de globalização da economia estabelecidas pelas instituições financeiras e pelas corporações internacionais.

Para Elza Guimarães Oliveira (2003), a EAD é um processo de reconstrução conceitual e metodológica, integrando o conhecimento objetivo ao subjetivo, ultrapassando o formalismo ins- 
taurado pela ciência moderna. Promove uma nova tecnologia de formação avançada através da comunicação digital, abrindo espaço para novas relações com pessoas, materiais tecnológicos, saberes. Sendo um novo espaço de construção, desconstrução e reconstrução do saber, na direção do aprender juntos e coletivamente. Com a aprendizagem participativa, surge a possibilidade de interação e criticidade.

Compreende-se, de fato, que a educação a distância pode ser uma alternativa para o país como o Brasil em que há a falta de eqüidade na distribuição de oportunidades educacionais levando a uma significativa redução de profissionais com possibilidades de capacitação e aperfeiçoamento. No entanto, ainda não se disseminou informações suficientes para uma compreensão mais profunda das possibilidades da educação à distância e dos fatores que tornam os sistemas e programas de EAD efetivos e de qualidade.

Compreende-se que a educação realizada pela tecnologia a distância não substitui a relação interpessoal direta, sendo necessária a integração para troca de experiências e construção coletiva, assim a tutoria torna o elo nessa interação. 0 sistema EAD gera a descaracterização do professor numa lógica de mercado para redução de gastos, em que a educação fica mais aligeirada devido o papel do professor formador ser retirada para a entrada de um professor tutor, tendo a idéia de diminuição da dependência da presença física do professor onde o aluno terá que buscar caminhos de interação com o aprender e terá uma melhora na parte tecnológica. Mostrando que a educação continua voltada à lógica do capital.

Assim, para se ter uma reforma dos sistemas educativos, Libâneo et al (2007) aborda que é necessário formular as estratégias de reforma em quatro pontos: o currículo nacional, a profissionalização dos professores, a gestão educacional e a avaliação institucional. Esses quatro pontos estão inter-relacionados, sendo assim: a política educacional orienta-se pela política curricular, que necessita de professores para ser viabilizada, em uma estrutura organizacional adequadamente regulada e gerida, com o suporte de avaliação institucional.

Nesse sentido, Seabra (2003, p.26-27) aponta o drama do ensino no país e o sentido dado as políticas públicas que imprimiu na educação a fragmentação e segmentação das escolas que ficaram inseridas nas políticas de ajuste do Banco Mundial, através dos seguintes pontos:

a) difunde-se a idéia de que o desemprego é desqualificação, ou seja, supostamente não existe um componente estrutural histórico, que o determina;

b) pensa-se que a escola tem de ter um caráter mais flexível. As carreiras do magistério, tanto quanto as seriações do ensino, são óbices que precisam ser demovidos;

c) a escola precisa ser paga. Pensa-se que o maior problema do ensino público, nos países pobres, consiste no fato de que quem pode pagar tem escola gratuita;

d) ocorre a exclusão do Estado do controle direto das escolas, portanto descentralizado do funcionamento, com controle pelas comunidades;

e) sugere-se um sistema nacional de avaliação com testes padronizados;

f) um sistema de avaliação, com hierarquização das escolas, resultaria em salário diferenciado aos professores.

Com a Legislação Educacional - LDB -percebe-se que as formações de planos e projetos para a "melhoria" da educação que no fundo só estão inseridas no objetivo de aumentar estatisticamente os quadros sobre a educação brasileira, e que no momento atual é feita de acordo com os poderes internacionais, FMl e Banco Mundial. 


\section{A LDB a serviço dos interesses dominantes}

$\mathrm{Na}$ conjuntura atual, a educação permanece a serviço dos interesses dos grupos - FMI e Banco Mundial -, que encontram na Legislação Educacional (LDB - Lei 9394/96) as possibilidades de formação educacional elaborada de acordo com os interesses desses grupos que investem nos países subdesenvolvidos através de empréstimos consentidos, indicando como e onde os recursos devem ser utilizados.

[...] dificuldades econômicas dos países latino-americanos possibilitou que o Banco Mundial passasse a monitorar as políticas macroeconômicas, criar os mecanismos de intervenção, propor modificações nas políticas econômicas e sociais dos Estados da América Latina e propugnar 0 alinhamento às políticas das instituições credoras (MONLEVADE; SILVA, 2000, p.76).

A década de 1990 foi marcada presença do Estado Avaliativo, orientado pela qualidade/ excelência, a avaliação da educação tornou-se foco de interesse, sendo averiguada por um sistema nacional de medidas. Seguindo os ditames dos órgãos internacionais, a educação foi marcada pela edição de inúmeras normatizações que deram um caráter determinante se limitando as leis estabelecidas na legislação de educação. A principal legislação foi a Lei de Diretrizes e Bases da Educação Nacional - LDB - de lei $n^{\circ}$ 9.394, sancionada pelo Presidente da República em 20 de dezembro de 1996.

Uma das determinações da LDB foi a criação um novo tipo de órgão formador de professores, que objetiva fomentar a exigência de que todos os professores em atividade tenham curso superior em 2007. Em agosto de 1999, o MEC autorizou a criação dos Institutos Superiores de Educação que poderão funcionar isoladamente ou integrados a universidades. 0 curso normal, em nível médio, continua sendo a formação mínima para o exercício da Educação Infantil e do ensino nas quatro séries iniciais do Ensino Fundamental. Os Institutos Superiores de Educação poderão oferecer cursos de magistério para a formação de professores de Educação Infantil (até 6 anos) e de séries iniciais (até a $4^{a}$ série do Ensino Fundamental) ou licenciatura para as séries iniciais. Para o Ensino Médio, serão oferecidos programas de atualização de professores (formação continuada) e programas especiais de formação pedagógica (para bacharéis de outras áreas). Também poderá ocorrer ensino de pós-graduação. Além das novas possibilidades para a formação de professores oferecida pelos Institutos de Educação, são mantidas as disciplinas de formação didática nos cursos de licenciatura (para cursos de graduação como Geografia, História, Química, etc) e a exigência de 60 horas de metodologia do ensino superior nos cursos de especialização (MOROSINI, 2000).

Deve-se compreender que a formação de professores está inserida nas mudanças do conhecimento científico relacionado ao papel da escola e à concepção de conhecimento escolar, e de profissão docente. Na atualidade têm-se muitas mudanças atribuídas à educação, e o professor tem a importante tarefa de transmitir o aparato de conteúdo e de técnicas à aprendizagem dos alunos, em que esta deve se dar por meio de situações práticas que sejam efetivamente problemáticas, 0 que exige o desenvolvimento de uma prática reflexiva competente e que garante, ao mesmo tempo, os nexos entre a formação inicial, a continuada e as experiências vividas.

Geografia Ensino \& Pesquisa, v. 17, n.1 p. 133-146, jan./abr. 2013

Os impasses da educação e a formação do professor em Geografia
É nessas relações que toma concretude a prática real da docência, do trabalho objetivo do professor. E é na prática de seus profissionais que a educação ganha corpo e realidade histórico-social. E nessa prática não estão em pauta apenas as circunstâncias que a conformam. Com efeito, ainda que as condições objetivas de caráter estrutural, relacionadas com a sociedade e com as instituições socioeducacionais, sejam fundamentais para a condução do processo educacional, não há como não vinculá-lo, naquilo que diz respeito à sua eficácia, às condições subjetivas da interação professor/alunos [...]. As mediações objetivas pressupõem, para ser eficazes, a participação subjetiva intencionalizante do educador. Por isso mesmo, a formação desse profissional é ponto central e tem merecido redobrada atenção dos estudiosos da educação (SEVERINO, 2003, p.73). 
A trajetória profissional é um processo complexo, em que há a interrelação das fases da vida e da profissão fundamentada para a constituição do profissional. Nessa interação se insere a trajetória profissional do ser professor, esse que através das diversas formas pedagógicas tem como função a produção do mundo educacional de um modo peculiar de modificá-lo de acordo com a concepção apreendida na sua formação profissional.

Nesse contexto insere-se a formação do professor de geografia, que de acordo com Callai (2006), tem importância inequívoca para o conhecimento tanto de sua ciência, e os fundamentos que the deram origem, assim como do pedagógico, do que significa aprender no sentido de construir um conhecimento próprio. Daí a ligação teoria/prática deve ter a perspectiva do pedagógico, do educador e da ciência com que se está trabalhando, para não cair em uma metodologia sem conteúdo.

Dessa maneira, torna-se importante a relação entre a produção do conhecimento, através dos cursos na Universidade, e a socialização do mesmo na prática educacional de sala de aula. Pois, a questão da formação dos profissionais da educação que atuarão em diversos níveis do sistema de ensino é objeto de permanente preocupação por parte de todos aqueles que se interessam pelos destinos da educação em qualquer sociedade.

\section{Currículo educacional e a geografia como disciplina}

O termo currículo num primeiro momento estava inserido na relação entre ordem e método, sendo primeiramente observado em registros do século XVII, sempre relacionado a um projeto de controle do ensino e da aprendizagem, ou seja, da atividade prática da escola. 0 currículo se define nesse período numa concepção tradicional, que no Brasil foi dominado pelas tendências do escolanovismo, no primeiro momento, e o tecnicismo num segundo, que dominaram o pensamento curricular de 1928 até final da década de 1960.

Já na década de 1970 surge a concepção de currículo num paradigma técnico-linear, e a crescente preocupação de formular currículos oficiais começam a surgir. Como cita Spósito (2006):
Os documentos oficiais, desde essa década, passaram, então, a orientar a formulação dos projetos pedagógicos escolares, os planos de ensino, as práticas educacionais e a elaboração dos materiais pedagógicos de apoio, sobretudo o livro didático. Os Guias Curriculares, conhecidos como 'Verdão', elaborados pela Secretaria de Educação do Estado de São Paulo, eram referenciais para apoiar a implantação da Lei $n^{\circ} 5.692 / 71$, de âmbito nacional (SPÓSITO, 2006, p.298)

A partir da década de 1980, num período marcado pela instauração da abertura política, houve o surgimento de um amplo debate sobre a questão educacional com a defesa da escola pública, com qualidade e democrática. Daí gerou a discussão sobre os currículos, ou seja, a problemática em torno dos conteúdos e metodologias trabalhados pelos professores nas escolas. Nesse período, as tendências teóricas para analisar a educação estavam centradas em duas posições distintas: a defendida pela Pedagogia dos Conteúdos - conteudistas - e a que defendia a Educação Popular - educadores populares.

Como aborda Albuquerque (2005) a posição defendida pelos conteudistas compreendia a escola como o espaço da difusão do saber sistematizado, e para que a escola cumprisse esse papel teria que ter uma metodologia que visasse a concretização desse processo na prática escolar. Já os educadores populares defendiam a interdisciplinaridade como forma de organização dos currículos e de produção dos saberes escolares, posição defendida por Freire em suas diferentes obras (1996; 1999 e 2001)2. Os conteudistas se posicionaram favoráveis à organização dos currículos tendo como referência a divisão do saber por disciplinas - pelo menos nos currículos que deram subsídio teórico.
2 As obras citadas por Albuquerque (2005) são as de Paulo Freire: Pedagogia da autonomia. $6^{a}$ ed. São Paulo: Paz e Terra, 1996; A educação na cidade. $3^{a}$ ed. São Paulo: Cortez, 1999; Pedagogia da esperança - um reencontro com a Pedagogia do oprimido. $8^{\mathrm{a}}$ ed. São Paulo: Paz e Terra, 2001.
Geografia Ensino \& Pesquisa, v. 17, n.1 p. 133-146, jan./abr. 2013

Shimada, S. O. 
Assim, torna-se nítido o acirramento dos debates entre essas duas grandes correntes nos estudos do currículo - a dos conteudistas e a dos educadores populares - que teorizam a questão curricular a partir da realidade brasileira, entre os estudiosos do currículo existe uma grande diferenciação nos seus pontos de vista. Com isso, os conteudistas defendem a adoção de um currículo que preze pelo conteúdo, como as teorias sociológicas, antropológicas e filosóficas européias; já os educadores populares propõem programas alternativos valorizando as práticas pedagógicas centradas na vida comunitária.

Dessa maneira é que o sistema educacional foi se organizando para a constituição do currículo em que este não deve ser fragmentado, mas sim gerando propostas para a democratização da escola pública e as reformulações curriculares.

Nessa dinâmica insere-se a Geografia como área de conhecimento que passa por mudanças nesse período através do processo de redefinição de seus paradigmas. Essa reflexão, de acordo com Marques (2008), surgiu desde a inserção da Geografia no currículo das séries iniciais. Assim, com a promulgação da Lei Orgânica do Ensino Primário e a Lei Orgânica do Ensino Normal em 1946 - conhecida Reforma Capanema - o ensino de Geografia começou a fazer parte do currículo oficial do ensino primário no país; pois, anteriormente, a geografia fazia parte de forma indireta.

Com a reforma da LDB de $n^{\circ} 5.692 / 71$ foi introduzida a matéria de Estudos Sociais no currículo escolar visando à substituição de História e Geografia, tendo como objetivo de alinhar o sistema educacional aos planos do estado capitalista brasileiro governado pelos militares. Ou seja, a legislação imposta de forma autoritária pelo Conselho Federal de Educação e pelos demais órgãos superiores, em plena ditadura militar, tinha "[...] a intenção de transformar a Geografia e a História em disciplinas inexpressivas no interior do currículo e, ao mesmo tempo, fragmentar mais ainda os respectivos conhecimentos" (PONTUSCHKA et. al., 2007, p.60).

Em meados da década de 1970 intensifica os movimentos para a democracia do país, evidenciando-se 0 impulso das teorias críticas especificamente com relação a geografia que gerou a partir da década de 80 a reintrodução das disciplinas de História e Geografia nas escolas.

De acordo com Castellar (2006), em meados da década de 1980 as propostas curriculares elaboradas em vários governos da América Latina tiveram como ponto de partida a Agenda Educacional para o século XXI que foi traçada pelo Banco Mundial. Essas reformas educacionais visavam a construção de um modelo educacional homogêneo, que tinham como objetivo obter um referencial único para a educação, criando assim os parâmetros mínimos para a educação - currículo, avaliação, formação docente, diretrizes para o ensino superior - democratizando o acesso à discussão e aos mesmos conteúdos mínimos nas escolas, criando referenciais para a estruturação do currículo. Nesse sentido, considerar em uma proposta curricular a realidade local passou a ser uma questão de método, sendo esta de responsabilidade da comunidade escolar ou das secretarias de Estado da Educação.

Nessa inserção do contexto histórico mundial e redução do papel do Estado - Estado mínimo -, é que no final da década de 1990 instituiu o projeto neoliberal, refletindo na educação através do surgimento dos Parâmetros Curriculares Nacionais para o cumprimento dos propósitos estabelecidos pelos organismos internacionais.

Com essa política educacional centralizadora que visava uma educação de qualidade foi introduzido propostas de temas transversais que criteriosamente foram selecionados como temas para serem desenvolvidos nas disciplinas escolares.

Geografia Ensino \& Pesquisa, v. 17, n.1 p. 133-146, jan./abr. 2013

Os impasses da educação e a formação do professor em Geografia
Para a escolha dos temas transversais, foram estabelecidos alguns critérios: urgência social, abrangência nacional, possibilidade de inclusão no currículo do ensino fundamental e favorecimento à compreensão da realidade à participação social. De acordo com esses critérios, os temas selecionados foram Ética, Meio Ambiente, Pluralidade Cultural, Saúde, Trabalho e Consumo, Orientação Sexual (PONTUSCHKA et. al., 2007, p.75). 
De acordo com Pontuschka et. al. (2007, p.81), no âmbito do ensino de geografia os PCN's estabelecem os seguintes objetivos:

- conhecer a organização do espaço geográfico e o funcionamento da natureza em suas múltiplas relações, a fim de compreender o papel das sociedades em sua construção e na produção do território, da paisagem e do lugar;

- identificar e avaliar as ações dos homens em sociedade e suas conseqüências em diferentes espaços e tempos, para construir referenciais que possibilitem uma participação propositiva e reativa nas questões socioambientais locais;

- compreender que as melhorias das condições de vida, os direitos políticos, os avanços técnicos e tecnológicos e as transformações socioculturais são conquistas decorrentes de conflitos e de acordos, as quais ainda não são usufruídas por todos os seres humanos. E, dentro das possibilidades, empenhar-se em democratizá-las;

- conhecer e saber utilizar procedimentos de pesquisa da Geografia para compreender o espaço, a paisagem, o território e o lugar, seus processos de construção, identificando suas relações, problemas e contradições;

- fazer leituras de imagens de dados e de documentos de diferentes fontes de informações, a fim de interpretar, analisar e relacionar informações sobre o espaço geográfico e as diferentes paisagens;

- saber utilizar a linguagem cartográfica para obter informações e representar a espacialidade dos fenômenos geográficos;

- valorizar o patrimônio sociocultural e respeitar a sociodiversidade, reconhecendo-a como um direito dos povos e indivíduos e um elemento de fortalecimento da democracia.

Dessa maneira os Parâmetros Curriculares Nacionais - PCN - de Geografia tinham como propostas para o ensino fundamental a ampliação dos alunos de suas capacidades de observar, conhecer, explicar, comparar e representar as características do lugar em que vivem e de diferentes paisagens e espaços geográficos. Para tanto, tem as orientações para o trabalho pedagógico que deverá apresentar os objetivos, eixos temáticos, conteúdos e critérios de avaliação; termina 0 documento com os procedimentos metodológicos.

E assim, tem-se uma redefinição da política educacional geradas na proposta dos PCN's, esta que foi imposta aos professores, surgindo dificuldades devido as disparidades dos municípios para o processo de ensino-aprendizagem e escolha de conteúdos que amplia os questionamentos sobre as oportunidades de acesso ao ensino qualificado.

Desse modo, compreende-se que o currículo e os programas educacionais são necessários para que se tenha uma educação escolar de qualidade, devendo está embasada na relação entre professores e alunos. Para tanto, a construção do Currículo será melhor desenvolvida com objetivo de organização do sistema de ensino se estabelecer intimamente ligada ao contexto social que está inserido na própria perspectiva do meio social, e que tem nas transformações tecnológicas a idéia de uma educação aligeirada para a lógica do sistema capitalista.

\section{Formação do professor em Geografia}

Diante dos impasses da educação, como fica o educador, sua formação profissional, atrelado a isso a geografia como disciplina que contextualiza o processo espaço-tempo com sua crítica a sociedade brasileira em questão?

A formação de professores enfrenta problemas na atualidade tanto no campo curricular como no campo institucional. Observa-se que no período da Ditadura militar houve uma reformulação do sistema escolar brasileiro, que implementou a desvalorização da carreira do docente. Sendo as-

Geografia Ensino \& Pesquisa, v. 17, n.1 p. 133-146, jan./abr. 2013

Shimada, S. O. 
sim, a educação e o professor tinham papéis negligenciáveis dentro da sociedade e com relação a disciplina geografia houve uma diminuição da carga horária atrelada a depreciação desta disciplina diante das outras na escola (VESENTINI, 2006).

Deve-se destacar que antes de 1934 o ensino da Geografia era feito por pessoas egressas de outros cursos, sendo somente desenvolvida como formação no Brasil a partir da fundação da Faculdade de Filosofia, Ciências e Letras da Universidade de São Paulo (FFCL/USP), em 1934, e do Departamento de Geografia, em 1946, que tiveram papéis fundamentais no desenvolvimento da ciência geográfica no país e na formação de licenciados para o ensino da disciplina. Atrelada à criação da USP, foi fundada a Associação dos Geógrafos Brasileiros (AGB), que teve e tem até hoje significativa importância para todos que, no Brasil, produzem conhecimento geográfico e/ou ensinam Geografia (PONTUSCHKA et al., 2007).

Com a criação da FFCL/USP houve mudança com relação ao perfil do professor de Geografia e História, pois possibilitou o surgimento do bacharel e do licenciado. $O$ aluno com sua formação docente em Geografia tornava-se um professor apto para ensinar História e Geografia. Somente em 1957, houve o desmembramento do curso de História e Geografia que passaram a ter vestibulares específicos para a entrada no curso superior.

Assim, nas últimas décadas do século XX têm-se uma massificação das escolas e dos professores, ao mesmo tempo em que ocorre uma depreciação econômica e social da atividade docente e da educação formal. Cacete (2006) afirma que os professores são vistos como profissionais despreparados sem capacidade de gerir autonomamente seus saberes.

O processo de mundialização da economia e a intensificação da tecnologia no mundo do trabalho e das comunicações geraram consequências para os conceitos de tempo e espaço, interferindo na relação entre teoria e prática. Contribuíram, assim, para formar professores com pouca autonomia no processo educativo (PONTUSCHKA, 2006).

Nesse ínterim as políticas públicas de formação de professor têm o discurso de valorização do profissional através do destino de verbas para a formação de professores, mas na prática não são compatíveis ao quantitativo de professores, e estes profissionais têm como resultante a desvalorização do professor através do recebimento de baixos salários.

Para o professor de geografia não é diferente, como cita Pontuschka (2006) que para ter o salário este profissional necessita dar um número bastante significativo de aulas, sem tempo de estudar e oferecer aos jovens uma formação geográfica rica em conteúdos, métodos e técnicas de análise que o ajudem a fazer a leitura do espaço, que vislumbre caminhos para o conhecimento do mundo e de aprender a se inserir de forma crítica e participativa nesse mundo em constante mudança.

Constata-se, assim, a importância da formação de professores que necessita de uma revisão profunda dos cursos de formação desses profissionais, para que haja uma interrelação entre projeto pedagógico e a organização institucional uma vez que a organização institucional tem um papel formador na medida em que fornece as condições de exequibilidade de um projeto curricular (CACATE, 2006).

Kaercher (2003) aborda que os educadores têm como necessário refletir, conflitar e romper desafios. Sendo importante a formação do professor em Geografia para contribuir na formação da sociedade.

A geografia é uma disciplina capaz de estabelecer um diálogo com o mundo real e comprometer-se com a leitura e as transformações das realidades desejadas, formando indivíduos com uma consciência crítica na construção de um raciocínio geográfico.

Os impasses da educação e a formação do professor em Geografia
A geografia é um saber estratégico e se desenvolve junto com a necessidade de compreensão do que é o mundo. Essas transformações, derivadas das recentes lógicas do capitalismo, exigem que a ciência geográfica passe por uma recontextualização [...]. Assim, para atender a essas novas demandas, o fazer geográfico não poderá mais estar alicerçado em velhas teorias e ideologias. (OLIVEIRA; TRINDADE, 2008, p.64) 
A Geografia é uma disciplina capaz de identificar a realidade e estabelecer uma consciência crítica e discernir a lógica do espaço geográfico. Pois o papel da geografia é "[...] priorizar a análise do espaço vivido e as práticas do espaço percebido, transpondo-as para as representações do espaço concebido. Devemos conhecer a psicogênese das operações e representações do espaço-temporal, assim como suas questões socioespaciais" (CASTROGIOVANNI, 2003, p.85).

Percebe-se, assim, a importância da formação do professor em Geografia para formar indivíduos críticos à transformação da sociedade atual. Para tanto, é preciso ter "[...] um ensino dinâmico, atual, criativo e instigante para que nossos alunos percebam a Geografia como um conhecimento útil e presente na vida de todos" (KAERCHER, 2006, p. 230).

Mas o que se percebe é que o sistema educacional brasileiro sempre foi formado de impasses e problemática, pois a educação e o professor não tinham um importante papel na sociedade como aborda Vesentini (2006, p.236) "[...] o fundamental era uma pequena formação técnica para a população em geral (encarada não como cidadãos e sim como força de trabalho), que as próprias empresas poderiam oferecer de forma mais eficaz do que as escolas", já o Estado sempre desempenhou papel fundamental para a prioridade ou não nesse processo. Evidencia-se assim que o ensino de geografia não era levado a sério, em principal porque levaria ao questionamento $\mathrm{e}$ formação crítica do aluno e isso nunca estivera em questão.

\begin{abstract}
é possível ver quais as políticas para a Educação no Brasil e que a Geografia era pensada a partir delas; quais os embates que os professores foram forçados a ter para garantir a sua autonomia profissional ou disciplinar, precipuamente no âmbito mais próximo das questões epistemológicas, como ocorreu, muitas vezes, com a imbricação da Geografia com outras disciplinas, sob diversas nomeações (Estudos Sociais, Estudos Regionais, Ciências Humanas etc.) ou ainda quando da diminuição efetiva da carga horária, decorrência da idéia de que outras disciplinas são mais importantes na formação escolar (FERNANDES, 2006, p. 245).
\end{abstract}

Destaca-se assim a importância dessa abordagem para formação de professores mais críticos imbricados a desenvolver uma geografia mais crítica para a formação de indivíduos que levem a uma mudança da sociedade brasileira e da própria educação que estão inseridas na lógica do capital.

\title{
Considerações
}

A formação do professor é necessária para estruturação de uma educação voltada para a qualidade do ensino na sociedade; nesse intuito, tem-se a importância de analisar o sistema educacional e identificando os impasses instituídos pela lógica do capital.

O governo brasileiro está integrado a mundialização do capital que tem nas mãos dos órgãos econômicos internacionais - FMI (Fundo Monetário Internacional) e BM (Banco Mundial) - o poder de dominação dos países dependentes do sistema capitalista. Dessa maneira, o Estado no processo de formação histórica sempre foi configurado a idéia de um pequeno grupo dominante da sociedade, e que na atualidade continua na sua lógica de estar a favor da classe dominante - como: usineiros, banqueiros, empreiteiros, fazendeiros - que leva a uma articulação desigual na sociedade.

Com isso todos os setores são corrompidos, entre eles a educação e o profissional docente em que as políticas educacionais são mudadas constantemente a cada novo governo, no entanto na prática tudo continua praticamente igual ao que era.

Por isso, a importância de compreender o ensino na lógica do capital para entender que o processo capitalista desestrutura todos os níveis educacionais, ou seja, desde a formação do professor na Universidade até o ensino na sala de aula; necessitando da participação de todos os envolvidos nesse processo para a mudança qualitativa ao sistema educacional.

Geografia Ensino \& Pesquisa, v. 17, n.1 p. 133-146, jan./abr. 2013

Shimada, S. O. 


\section{Referências bibliográficas}

ALBUQUERQUE, Maria Adailza Martins de. "Currículos de Geografia: da abertura política aos PCN's". In: Mercator - Revista de Geografia da UFC, ano 04, n07, 2005. Disponível em < http://www.mercator.ufc.br/index.php/mercator/article/viewFile/110/82 > acessado em 20/03/2009.

CACETE, Núria Hanglei. "A formação de professores e os contextos institucionais". In: SILVA, José Borzacchiello da [et al.] (orgs.). Panorama da Geografia Brasileira II. São Paulo: Annablume, 2006, p.243-248.

CALLAI, Helena Copetti. "Projetos interdisciplinares e a formação do professor em serviço". In: PONTUSCHKA, N.N.; OLIVEIRA, A.U. de (orgs.). Geografia em perspectiva: ensino e

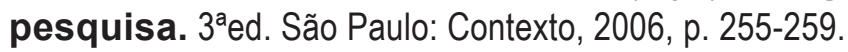

CASTELLAR, Sônia Maria Vanzella. "Currículo, educação geográfica e formação docente: desafios e perspectivas". In: Revista Tamoios, UFRJ, ano II, n² 2, julho/dezembro 2006. Disponível em < http://br.geocities.com/revistatamoios/revistas/0602/curriculo.htm > acesso em: 01/04/2009.

CASTROGIOVANNI, Antônio Carlos. "E agora, como fica o ensino da geografia com a globalização?". In: Geografia em sala de aula - práticas e reflexões, CASTROGIOVANNI, A.

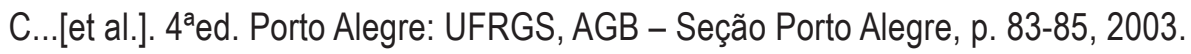

FERNANDES, Manoel. "Reflexões sobre a investigação em história da formação de professores de geografia". In: PONTUSCHKA, N.N.; OLIVEIRA, A.U. de (orgs.). Geografia em perspectiva: ensino e pesquisa. $3^{a}$ ed. São Paulo: Contexto, 2006, p. 241-246.

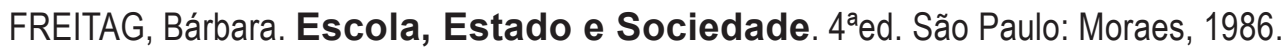

GADOTTI, Moacir. Perspectivas atuais da educação. Revista eletrônica São Paulo em Perspectiva, 14 (2), 2000, p. 3-7.

KAERCHER, Nestor André. "Estudos Sociais: reflexões, conflitos e desafios". In: Geografia em sala de aula - práticas e reflexões, CASTROGIOVANNI, A. C...[et al.]. $4^{\mathrm{a} e d}$. Porto Alegre: UFRGS, AGB - Seção Porto Alegre, 2003, p. 49-55.

KAERCHER, Nestor André. "O gato comeu a geografia crítica? Alguns obstáculos a superar no ensino-aprendizagem de geografia". In: PONTUSCHKA, N.N.; OLIVEIRA, A.U. de (orgs.). Geografia em perspectiva: ensino e pesquisa. $3^{a}$ ed. São Paulo: Contexto, 2006, p. 221-231.

LIBÂNEO, José Carlos; OLIVEIRA, João F. de; TOSCHI, Mirza Seabra. Educação Escolar: políticas, estrutura e organização. $5^{\mathrm{a}}$ ed. São Paulo: Cortez, 2007. Coleção Docência em Formação.

MARQUES, Valéria. Reflexões sobre o ensino de Geografia nas séries iniciais do ensino fundamental. In: Revista Virtual P@rtes, 05/12/2008. Disponível em < http://www.partes.com.br/ educacao/geografiafundamental.asp > acesso em: 28/03/2009.

Geografia Ensino \& Pesquisa, v. 17, n.1 p. 133-146, jan./abr. 2013

Os impasses da educação e a formação do professor em Geografia
MÉSZÁROS, István. A teoria da alienação em Marx. São Paulo: Boitempo, 2006. Tradução Isa Tavares.

MONLEVADE João A.; SILVA, Maria Abadia da. Quem manda na Educação no Brasil?. Brasília: IDEA, 2000.

MOROSINI, Marília Costa. "Docência universitária e os desafios da realidade nacional". In: MO- 
ROSINI, Marília Costa (org.). Professor do ensino superior: identidade, docência e formação, Brasília: Instituto Nacional de Estudos e Pesquisas Educacionais, 2000, p.11-20. Disponível em < http://antigo.inep.gov.br/download/cibec/2000/titulos_avulsos/miolo-professor-do-ensino-superior.pdf > acesso em 20/03/2009.

OLIVEIRA, C.G.S.; TRINDADE, G.A. "Ensino de geografia e reflexões acerca da (re)construção do currículo no âmbito da licenciatura". In: TRINDADE, G.A.; CHIAPETTI, R.J.N (orgs.). Discutindo Geografia: doze razões para se (re)pensar a formação do professor. llhéus: Editus, UESC, 2008, p.63-79.

OLIVEIRA, Elsa Guimarães. Educação à distancia na transição paradigmática. São Paulo: Papirus, 2003.

Plano Nacional de Educação - A proposta da Sociedade Brasileira/PNE. Belo Horizonte, 1997. Consolidado na Plenária de Encerramento do II CONED.

PONTUSCHKA, Nídia Nacib. "A formação geográfica e pedagógica do professor". In: SILVA, José Borzacchiello da [et al.] (orgs.). Panorama da Geografia Brasileira II. São Paulo: Annablume, 2006, p.269-279.

PONTUSCHKA, N. N.; PAGANELLI, T. I.; CACETE, N. H. Para ensinar e aprender Geografia. São Paulo: Cortez, 2007.

ROMANELLI, Otaíza de Oliveira. História da Educação no Brasil (1930-1973). $17^{\mathrm{a}} \mathrm{ed}$. Rio de Janeiro: Vozes, 1995.

SEABRA, Odette Carvalho de Lima. "Educação, território e cidadania: aprender a aprender ensinando". In: Geografia em sala de aula - práticas e reflexões, CASTROGIOVANNI, A. C... [et al.]. $4^{a}$ ed. Porto Alegre: UFRGS, AGB - Seção Porto Alegre, p. 23-30, 2003.

SEVERINO, Antônio Joaquim. "Preparação técnica e formação ético-política dos professores". In: BARBOSA, Raquel Lazzari Leite (org.). Formação de educadores: Desafios e perspectivas. São Paulo: UNESP, 2003, p. 71-89. Disponível em < http://www.dominiopublico.gov.br/ download/texto/up000019.pdf\#page=256> acesso em 03/04/2009.

SPÓSITO, Maria Encarnação. "As diferentes propostas curriculares e o livro didático". In: PONTUSCHKA, N.N.; OLIVEIRA, A.U. de (orgs.). Geografia em perspectiva: ensino e pesquisa.

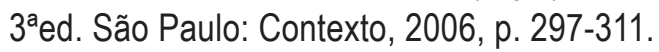

VESENTINI, José Willian. "Formação do professor de geografia - algumas reflexões". In: PONTUSCHKA, N.N.; OLIVEIRA, A.U. de (orgs.). Geografia em perspectiva: ensino e pesquisa. $3^{\mathrm{a} e d .}$ São Paulo: Contexto, 2006, p. 235-240. 


\section{Correspondência:}

Shiziele de Oliveira Shimada- Rua Adalto Barbosa da Costa, 504, Bairro Bugio, Aracaju-Sergipe, CEP 49090-730 Brasil

E-mail: shiziele@bol.com.br

Recebido em 02 de janeiro de 2012.

Revisado pelo autor em 04 de janeiro de 2013.

Aceito para publicação em 02 de fevereiro de 2013. em Geografia 